\title{
Sensitivity of quantitative precipitation forecasts to boundary layer parameterization: a flash flood case study in the Western Mediterranean
}

\author{
M. Zampieri, P. Malguzzi, and A. Buzzi \\ ISAC - CNR, Via Gobetti 101, I-40129 Bologna, Italy
}

Received: 29 March 2005 - Revised: 17 June 2005 - Accepted: 28 June 2005 - Published: 3 August 2005

Part of Special Issue "HYDROPTIMET"

\begin{abstract}
The "Montserrat-2000" severe flash flood event which occurred over Catalonia on 9 and 10 June 2000 is analyzed. Strong precipitation was generated by a mesoscale convective system associated with the development of a cyclone. The location of heavy precipitation depends on the position of the cyclone, which, in turn, is found to be very sensitive to various model characteristics and initial conditions.

Numerical simulations of this case study using the hydrostatic BOLAM and the non-hydrostatic MOLOCH models are performed in order to test the effects of different formulations of the boundary layer parameterization: a modified version of the Louis (order 1) model and a custom version of the $E-\ell$ (order 1.5) model. Both of them require a diagnostic formulation of the mixing length, but the use of the turbulent kinetic energy equation in the $E-\ell$ model allows to represent turbulence history and non-locality effects and to formulate a more physically based mixing length.

The impact of the two schemes is different in the two models. The hydrostatic model, run at $1 / 5$ degree resolution, is less sensitive, but the quantitative precipitation forecast is in any case unsatisfactory in terms of localization and amount. Conversely, the non-hydrostatic model, run at 1/50 degree resolution, is capable of realistically simulate timing, position and amount of precipitation, with the apparently superior results obtained with the $E-\ell$ parameterization model.
\end{abstract}

\section{Introduction}

Flood forecasting at short range has taken advantage, in recent years, from the improvement in quality and spatial resolution of meteorological numerical models, used for quantitative precipitation forecast (QPF) in deterministic or prob-

Correspondence to: M. Zampieri

(m.zampieri@isac.cnr.it) abilistic mode. However, the presence of powerful atmospheric instabilities, as baroclinic instability on the synoptic and sub-synoptic scales and convective instability on the smallest mesoscale, is at the origin of forecast errors due to sensitivity to initial conditions and model deficiencies. QPF, being related to both instabilities, especially convective instability, is particularly sensitive and prone to such errors.

In the present paper, we study the sensitivity of QPF to different schemes applied to parameterize turbulent exchanges in the planetary boundary layer (PBL). The PBL is the region of the atmosphere, close to the surface, where the turbulent fluxes are important to determine the various processes that affect atmospheric dynamics. Recent studies (Xu and Zhao, 2000; Lynn et al., 2001; Wisse and de Arellano, 2004) have shown that the evolution of precipitating systems, and convective systems in particular, is very sensitive to the PBL parameterization and, in particular, can take advantages of the application of higher order turbulence closure schemes.

The numerical tests are conducted with two different models, both developed at ISAC: a hydrostatic model (BOLAM), capable of representing baroclinic instability and related mesoscale phenomena, and a non-hydrostatic model (MOLOCH), applied at very high horizontal resolution such that convective phenomena, and associated precipitation processes, can be resolved in a sufficiently realistic way to allow direct QPF. The non-hydrostatic model runs are nested into the hydrostatic model grid.

The "Montserrat-2000" case study (Llasat et al., 2003), also described by Mariani et al. (2005), occurred on 9 and 10 June 2000 over the northeastern Iberian Peninsula. Heavy rain and flooding affected especially the Llobregat basin (Catalonia), near the Montserrat mountain. This event is characterized by an interaction between a baroclinically unstable wave and the topography, generating complex mesoscale dynamics, and by the development of severe convection, dynamically associated with the larger scale evolution. 
A detailed synoptic description of the event is not given here, because it is already presented in the quoted and in other papers (appearing in this same issue) connected with the EU Project Hydroptimet (INTERREG III-B MEDOCC), in the context of which also this study is performed. It is sufficient to note here that the main system that caused more than $220 \mathrm{~mm}$ of rain (half of which fallen in the period between 02:00 and 05:00 UTC of 10 June) and flooding was an organized and long lasting mesoscale convective system (MCS) that assumed the form of an elongated squall line moving slowly from SW to NE. It was associated with the convergence of warm and moist air inflow from a southeasterly low level jet (warm conveyor belt), developed over the Western Mediterranean in association with low level cyclogenesis, and of a drier and colder north-easterly low level flow turning anticiclonically around the eastern tip of the Pyrenees (see also Sect. 44.2 and Fig. 12)

The presence of such a complex and orographically modified mesoscale flow, together with strong embedded convection, makes this case particularly interesting for model experiments (Romero et al., 2005) and model intercomparison (Mariani et al., 2005), but, at the same time, prevents the formulation of a simple interpretation of the results in terms of model induced changes. Therefore, our purpose here is to present the sensitivity of QPF to different turbulence parameterizations schemes and not to compare, for instance, PBL profiles, which would require a less complex and rapidly evolving situation.

The turbulent fluxes are not explicitly resolved by the meteorological models and thus they have to be parameterized. The mixing length (ML) based turbulence closure models are widely used to compute the PBL fluxes for atmospheric modeling applications because they are simple and they give reliable and stable results. In principle, the parameterized ML can enter any model that avoids the prognostic computation of the turbulence dissipation. The discussion here regards only models in which the ML is the most important factor in determining turbulent mixing. These models can be either of order 1 , in which turbulence is assumed to be stationary and to be completely determined by the local flow variables, or of order 1.5, in which the turbulent kinetic energy (TKE) is predicted by an equation that allows to take into account the effects of history and non-locality of turbulence.

The order 1 models commonly use the Blackadar (1962) mixing length that applies well to the neutral boundary layer. To take into account buoyancy effects, the Blackadar ML is used together with stability functions (SF) that depend on the Richardson number and that are intended to generalize the application of the theory for either statically stable or unstable cases. Louis (1979) proposed a method of deriving the SF from the Monin and Obukhov (1955) similarity theory, that is used to compute the surface fluxes. After that, the definition of different SF evolved independently, being in fact one of the major tuning parameters to improve model performance (Beljaars, 1995). Here a modified set of the Louis $\mathrm{SF}$ is proposed to be coherent with the version of similarity theory that is actually used in the present study.
The order 1 model assumes stationarity and locality of turbulence. In order to overcome these limitations, the $E-\ell$ model is introduced: this model makes use of the TKE equation, that is virtually capable to reproduce history and nonlocality effects (Rodi, 1980; Speziale, 1991). Moreover, the use of the TKE equation allows to define a more physical parameterization of the ML formulation for the stable case that avoids the use of the SF, while for the unstable case a modified version of the non-local "parcel-like" mixing length of Bougeault and Lacarrere (1989), obtained as a result of the implementation of a third order model (Canuto et al., 1994) by Zampieri (2004), is used.

The paper is organized as follows: in Sect. 2 the two PBL parameterizations are described. An essential description of the main characteristics of the models is given in Sect. 3 . The results of the simulations performed with the two different models are presented and discussed in Sect. 4. The conclusions are drawn in Sect. 5.

\section{The turbulence closure models}

The equations for vertical diffusion within the atmosphere can be written as:

$$
\frac{\partial \boldsymbol{U}(z)}{\partial t}=\frac{\partial}{\partial z}\left(K_{m}(z) \frac{\partial \boldsymbol{U}(z)}{\partial z}\right)
$$

and

$\frac{\partial \Theta(z)}{\partial t}=\frac{\partial}{\partial z}\left(K_{h}(z) \frac{\partial \Theta(z)}{\partial z}\right)$,

where $\boldsymbol{U}=(U, V)$ is the horizontal mean wind and $\Theta^{1}$ is the mean potential temperature. The terms on the right hand side represent the divergence of the turbulent fluxes, for which the Boussinesq approximation for turbulence (Hinze, 1975) is assumed. $K_{m}$ and $K_{h}$ are, respectively, the eddy kinematic viscosity and the eddy thermal diffusivity whose ratio defines the turbulent Prandtl number $\left(P r \equiv K_{m} / K_{h}\right)$.

In the mixing length models, the eddy viscosity and diffusivity are parameterized as a length scale multiplied by a velocity scale (Rodi, 1980). Thus,

$K_{m}=\ell_{m} u_{t}, \quad K_{h}=\ell_{h} u_{t}$

where $\ell_{m}$ and $\ell_{h}$ are the ML for momentum and heat and $u_{t}$ the turbulent velocity scale.

\subsection{Louis (order 1) model}

In the order 1 models the velocity scale is defined (Prandtl, 1932; see also Stull, 1988) as:

$u_{t}=\ell_{m}\left|\frac{\partial \boldsymbol{U}}{\partial z}\right|$.

In the neutral case $(R i=0)$, the ML is defined with a modified Blackadar (1962) formula:

$$
\frac{1}{\ell_{n}(z)}=\frac{1}{\kappa z}+\frac{1}{\ell_{\infty} \beta(z)}
$$

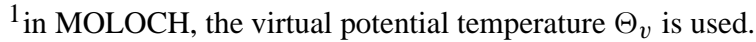


where $\kappa$ is the von Kármán constant, $\ell_{\infty}=150 \mathrm{~m}$ and the parameter $\beta$, that was not included in the original formula, is equal to 1 in the boundary layer but reduces the effective length scale above the boundary layer in order to prevent excessive mixing to occur in and around the jet stream (Beljaars and Viterbo, 1999; Viterbo et al., 1999).

Louis (1979) defined the eddy diffusion coefficients in a stratified environment as:

$$
\begin{aligned}
& K_{m}=\ell_{n}^{2}(z) \cdot F_{m}(R i)\left|\frac{\partial \boldsymbol{U}}{\partial z}\right| \\
& K_{h}=\ell_{n}^{2}(z) \cdot F_{h}(R i)\left|\frac{\partial \boldsymbol{U}}{\partial z}\right|,
\end{aligned}
$$

where $R i$ is the gradient Richardson number that quantifies the environmental effects on turbulence:

$$
R i=\frac{g}{T_{v}} \frac{\frac{\partial \Theta_{v}}{\partial z}}{\left(\frac{\partial U}{\partial z}\right)^{2}+\left(\frac{\partial V}{\partial z}\right)^{2}},
$$

where $T_{v}$ is the virtual absolute temperature and $\Theta_{v}{ }^{2}$ is the virtual potential temperature.

The main difficulty is in the specification of the stability functions $(\mathrm{SF})$. Louis proposed the following analytical forms:

$$
\begin{aligned}
& F_{\psi}(R i)=1-\frac{b_{\psi} R i}{1+C_{H}(-R i)^{\frac{1}{2}}}, \\
& C_{H}=b_{\psi} c_{\psi} \ell_{n}^{2} \frac{\left((z+\Delta z / z)^{1 / 3}-1\right)^{3 / 2}}{z^{1 / 2} \Delta z^{3 / 2}} \quad \forall R i<0
\end{aligned}
$$

and

$$
\begin{aligned}
& F_{h}(R i)=\frac{1}{1+d_{h} R i\left(1+e_{h} R i\right)^{\frac{1}{2}}}, \\
& F_{m}(R i)=\frac{1}{1+d_{m} R i\left(1+e_{m} R i\right)^{-\frac{1}{2}}} \quad \forall R i>0,
\end{aligned}
$$

where $\psi=m, h$, and where $\Delta z$ is the vertical grid spacing.

In the present study, the stability functions (SF) are derived by analogy with the Monin and Obukhov (1955) similarity theory coherently with the values $\operatorname{Pr}=1$ (in the case of neutral stratification) and $\kappa=0.4$ (Hogstrom, 1988; Hogstrom, 1996). The similarity functions are those of Dyer for the unstable case (Dyer, 1974) and those of Beljaars for the stable case (Beljaars and Holtslag, 1991). Hence the Louis procedure is repeated in order to maintain consistency between surface and PBL turbulent fluxes. This gives the revised set of the SF coefficients: $b_{m}=20, b_{h}=17, c_{m}=7.5, c_{h}=4.2$, $d_{m}=b_{m} / 2, d_{h}=b_{h} / 2, e_{m}=1, e_{h}=\left(b_{m} / b_{h}\right)^{2}$.

\section{$2.2 E-\ell$ (order 1.5) model}

In order to take into account the history and transport effects of turbulence, the velocity scale can be linked to the TKE

\footnotetext{
${ }^{2}$ In a saturated atmosphere, the equivalent potential temperature $\Theta_{e}$ is used in place of $\Theta_{v}$.
}

(Kolmogorov, 1942; Prandtl, 1945; see also Rodi, 1980 or Speziale, 1991 for a review):

$u_{t}=\left(c_{E} E(z)\right)^{1 / 2}$,

where $E$ is the TKE and where $c_{E}=0.17$ (Panofsky et al., 1977).

The ML for heat is assumed to be equal to the one for the momentum. After Eq. (2), the eddy viscosity and diffusivity become:

$K_{m}=\ell_{m}\left(c_{E} E(z)\right)^{\frac{1}{2}}, \quad K_{h}=K_{m} \quad(P r=1)$.

The TKE equation can be written, in the boundary layer approximation, as:

$$
\begin{aligned}
\frac{d E(z)}{d t} & =\frac{\partial}{\partial z}\left(K_{m} \frac{\partial E(z)}{\partial z}\right)+K_{m}\left(\left(\frac{\partial U(z)}{\partial z}\right)^{2}+\left(\frac{\partial V(z)}{\partial z}\right)^{2}\right) \\
& -\frac{g}{T_{v}(z)} K_{h} \frac{\partial \Theta_{v}(z)}{\partial z}-\frac{\left(c_{E} E(z)\right)^{3 / 2}}{\ell_{m}},
\end{aligned}
$$

where the turbulent flux of TKE in the first term on the R.H.S and the turbulent fluxes in the production and destruction terms (the second and the third term) are modeled according to the Boussinesq hypothesis, that is a simple downgradient expression, as for the momentum flux in Eq. (1). In Eq. (12), the pressure correlations are incorporated into the TKE flux. The last term on the R.H.S. of Eq. (12), representing the TKE dissipation, is modeled according to the Kolmogorov (1941) hypothesis, using the same ML of the momentum diffusion. The relation $c_{E} E(0)=u_{*}^{2}$, where $u_{*}$ is the friction velocity, is used as boundary condition for the TKE at the surface. An additional term, proportional to the convective velocity scale (Deardorff, 1970), can be considered at the surface to parameterize the wind gustiness.

In the unstable case, turbulence is characterized by a nonlocal behaviour. Thus, it is convenient to use a non-local ML formulation (Bougeault and Lacarrere, 1989) that avoids the use of the local SF. The non-local ML for the unstable case can be defined (Zampieri, 2004) as:

$\ell_{m}=\ell_{h}=c_{U}\left(\left(z_{\text {up }}-z\right)\left(z-z_{\text {down }}\right)^{3}\right)^{1 / 4}$,

$z_{\text {down }}<z<z_{\text {up }}$,

where $c_{U}=0.5$ and where $z_{\text {down }}$ and $z_{\text {up }}$ are the heights of the bottom and top boundaries of the unstable layer, respectively.

In the stable case, the ML can be parameterized through the balance between the TKE and the potential energy $E_{P} \equiv \ell^{2} N^{2}$, where $N^{2}$ is the Brunt-Väisälä frequency. Thus, the ML can be defined (Deardorff, 1980) as follows:

$\ell_{S}=c_{S}\left(\frac{E}{N^{2}}\right)^{\frac{1}{2}}$,

where $c_{S}$ is a closure parameter. This is not a stand-alone definition because it is singular in the neutral limit. To avoid this problem, and to match the similarity theory near the surface, Eq. (14) is combined with a Blackadar (1962) ML expression similar to Eq. (4). It follows:

$\frac{1}{\ell_{m}}=\frac{1}{k z}+\frac{1}{\ell_{\infty}}+\frac{1}{\ell_{S}}$, 
where $\ell_{\infty}=75 \mathrm{~m}$.

The closure parameter $c_{S}$ can be set in order to match the typically observed Richardson number well above the surface, where $\ell_{m} \ll k z$ and where turbulence can be considered almost height independent. Assuming also $\ell_{m} \ll \ell_{\infty}$, only the stability-dependent term survives in Eq. (15) and, from the TKE equation (12) under the assumptions of stationarity and locality, one finds

$c_{E}=\left(\frac{c_{S}}{N}\right)^{2}\left(\left(\frac{\partial U}{\partial z}\right)^{2}+\left(\frac{\partial V}{\partial z}\right)^{2}-\frac{g}{T_{v}} \frac{\partial \Theta_{v}}{\partial z}\right)$

Using the definition of the Richardson number (7), a relation for $c_{S}$, that depends on the Richardson number itself, is found:

$c_{S}=\left(c_{E} \frac{R i}{1-R i}\right)^{\frac{1}{2}}$

that, with a typical $R i \simeq 0.2$ (Nieuwstadt, 1984), gives $c_{S} \simeq 0.2$.

The ML computed with Eq. (15) is applied to the momentum and heat diffusion, implying $P r=1$. The use of such a Prandtl number produces a critical Richardson number that corresponds to a stability situation in which turbulence is completely suppressed. In fact, from Eq. (12), assuming locality and stationarity and imposing zero TKE and $\operatorname{Pr}=1$, one finds $R i_{c}=1$, that is in agreement with measurements and LES data (Webster, 1964; Young, 1975; Wang et al., 1996).

\section{Model descriptions}

\subsection{BOLAM}

BOLAM is a meteorological model based on primitive equations in the hydrostatic approximation (Buzzi et al., 1994). It uses sigma-coordinates and wind components, potential temperature, specific humidity and surface pressure and five hydrometeors (cloud ice, cloud water, rain, snow, graupel) as prognostic quantities. Variables are distributed on a nonuniformly spaced Lorenz grid. The horizontal discretization uses geographical coordinates, with latitudinal rotation on an Arakawa C-grid. The model implements a Weighted Average Flux (WAF, Billet and Toro, 1997) scheme for the three dimensional advection. The lateral boundary conditions are imposed using a relaxation scheme that minimizes wave energy reflection. The water cycle for stratiform precipitation is described by means of five prognostic variables (cloud ice, cloud water, rain, snow, graupel), with a simplified approach similar to that proposed by Schultz (1995). Deep convection is parameterized, using the Kain-Fritsch (Kain and Fritsch, 1990; Kain, 2004) convective scheme. The surface and boundary layer schemes are discussed in detail in the previous section. Soil processes consist of water and energy balances in a three-layer ground model described in Buzzi et al. (1994). Radiation is computed with a combined application of the Ritter and Geleyn (1992) scheme and the ECMWF scheme (Morcrette, 1991; Mlawer et al., 1997). The orography used in the simulations is derived from interpolation and smoothing of the 1/120 degree resolution GLOBE Digital Elevation Model.

\section{$3.2 \mathrm{MOLOCH}$}

MOLOCH is a non-hydrostatic, convection resolving model developed at the ISAC. It integrates the fully compressible set of equations with prognostic variables (pressure, temperature, specific humidity, horizontal and vertical velocity components, and four water species) represented on the lat-lon rotated Arakawa C-grid. Terrain following coordinates, relaxing smoothly to horizontal surfaces away from the earth surface, are employed. Model dynamics is integrated in time with an implicit scheme for the vertical propagation of sound waves, while explicit, time-split schemes are implemented for the remaining terms. Three dimensional advection is computed using the accurate WAF scheme (as for BOLAM) and the semilagrangian scheme. Horizontal fourth order diffusion and divergence damping are included to prevent energy accumulation on the shorter space scales. The physical component includes radiation, sub-grid turbulence, microphysics, and soil water and energy balance. The microphysical scheme is based on the parameterization proposed by Drofa and Malguzzi (2004). The physical processes determining the time tendency of specific humidity, cloud water/ice and precipitating water/ice are divided into "fast" and "slow" ones. Fast processes involve transformations between specific humidity and cloud quantities and are computed every advection time step. Temperature is updated by imposing exact entropy conservation at constant pressure. Fall of precipitation is computed with the stable and dispersive backward-upstream scheme with fall velocities depending on concentration. The surface and boundary layer schemes are discussed in detail in the previous section. The soil scheme, derived from the parameterization of Pressman (1994), has been recently developed. It evaluates water and heat balance in 4 soil layers with diagnostic computation of skin temperature and humidity at the interface with the atmosphere. Seasonally dependent vegetation effects are considered, including evapo-transpiration and interception of precipitation. Soil physical properties (heat and water conductivity and capacity) are specified on the basis of the FAO dataset at $1 / 12$ degree resolution. The radiation scheme is the same as in BOLAM.

\section{Numerical experiments}

\subsection{BOLAM simulations}

The event has been simulated using the BOLAM model at 1/5 degree resolution starting at 00:00 UTC of 9 June 2000. The model grid comprises $160 \times 160$ points with 38 vertical levels. Differently from the model version used by Mariani et al. (2005), the new Kain-Fritsch parameterization of moist convection (Kain, 2004) has been implemented, and 


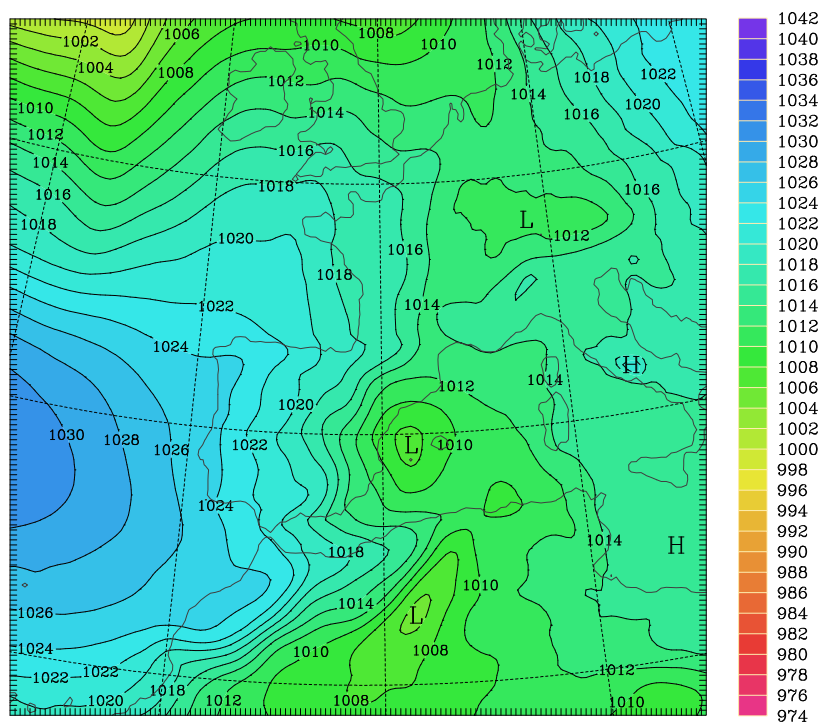

Fig. 1. ECMWF MSLP analysis at 10 June, 00:00 UTC.

the ECMWF analyses are used (instead of forecasts) to specify initial and lateral boundary conditions.

In Figs. 1, 2 and 3, the mean sea level pressure from the ECMWF analysis and the BOLAM simulations with the Louis (hereafter referred to as B-L) and the $E-\ell$ (BEL) boundary layer schemes, respectively, are shown at 00:00 UTC of 10 June. The area depicted corresponds to the entire model domain excluding the boundary frame, where relaxation to boundary conditions is forced. Over the previous few hours, a surface depression has formed, between the Catalonia coast and the Balearic Islands, with a minimum pressure less than $1008 \mathrm{hPa}$ (see Fig. 1). Sensitivity experiments have shown that cyclone development is modified and localized by the orographic forcing, in the presence of an upper level potential vorticity maximum coming from the Atlantic. This time corresponds to the beginning of the period of most intense precipitation over Catalonia, which can be traced in the interval between 00:00 and 06:00 UTC of 10 June.

Both B-L and B-EL experiments reproduce the cyclogenetic process with the minimum pressure located at the right position, although the cyclone intensity and relative vorticity seem somewhat overestimated, especially in B-EL. Other differences between B-L and B-EL experiments relative to this field are very small.

Synoptic and sub-synoptic features associated with the cyclone are evident in Figs. 4 and 5 which show, respectively, the infrared NOAA image at 04:26 UTC of 10 June (around the time of maximum rainfall rate) and the cloud cover of the B-L experiment. A northerly upper level jet from Ireland to the western Iberian peninsula turns cyclonically over the Alboran sea, ending in the "dry intrusion" visible west of the Balearic Islands. The "cloud head", in which the mesoscale convective system is embedded, is located over Catalonia, to the north west of the dry intrusion. The cloudy region

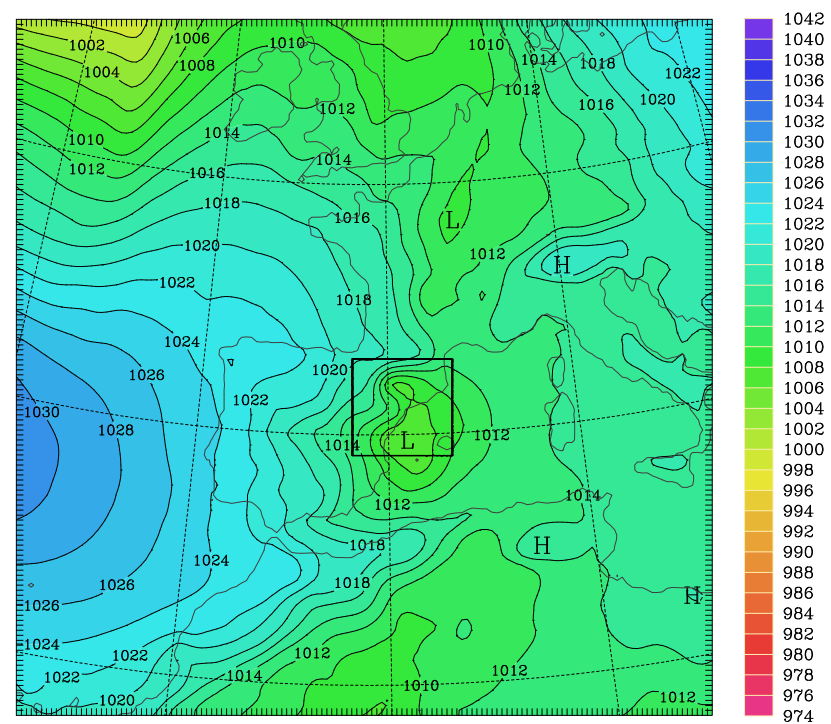

Fig. 2. 24-h MSLP forecast valid at 10 June, 00:00 UTC. BOLAM model with the Louis PBL scheme (B-L experiment). The box indicates the MOLOCH domain.

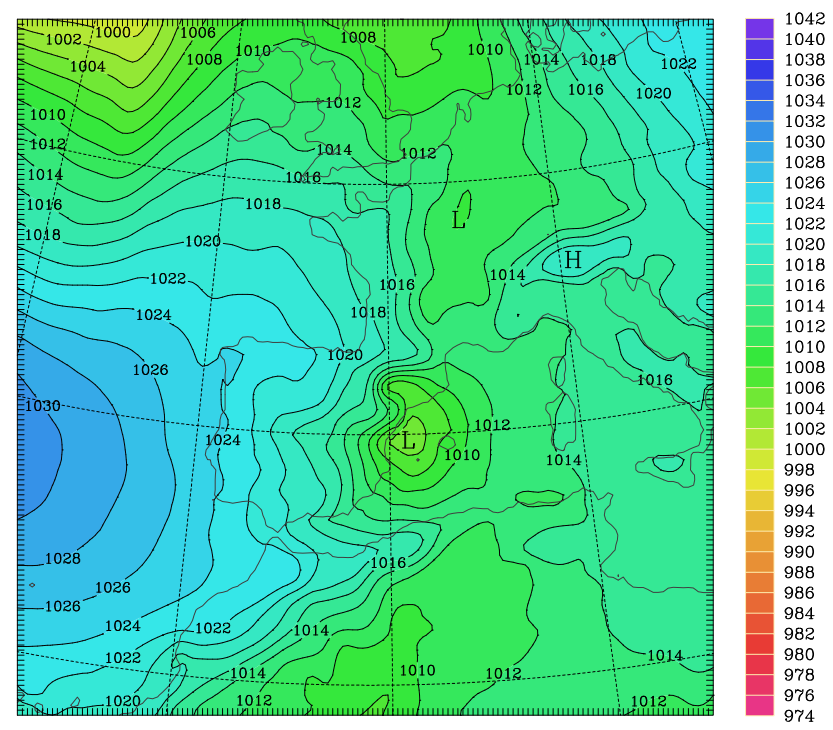

Fig. 3. 24-h MSLP forecast valid at 10 June, 00:00 UTC. BOLAM model with the $E-\ell$ PBL scheme (B-EL experiment).

affected by the strongest warm advection covers the "warm conveyor" belt (Browning, 1990), which turns cyclonically and becomes almost perpendicular to the coast of Catalonia. The agreement between observed and simulated cloud cover is remarkable.

Figures 6, 7, and 8 show, respectively, the observed and simulated precipitation, accumulated in the 24 -h time interval extending from 12:00 UTC of 9 June to 12:00 UTC of 10 June, for the B-L and B-EL experiments. The observed precipitation has been obtained by using the raingauge data, limited to the Catalonia region, presented in Llasat et al. (2003) and reanalyzed over the 1/50 degree grid of the MOLOCH model. Note that the BOLAM precipitation is presented on 


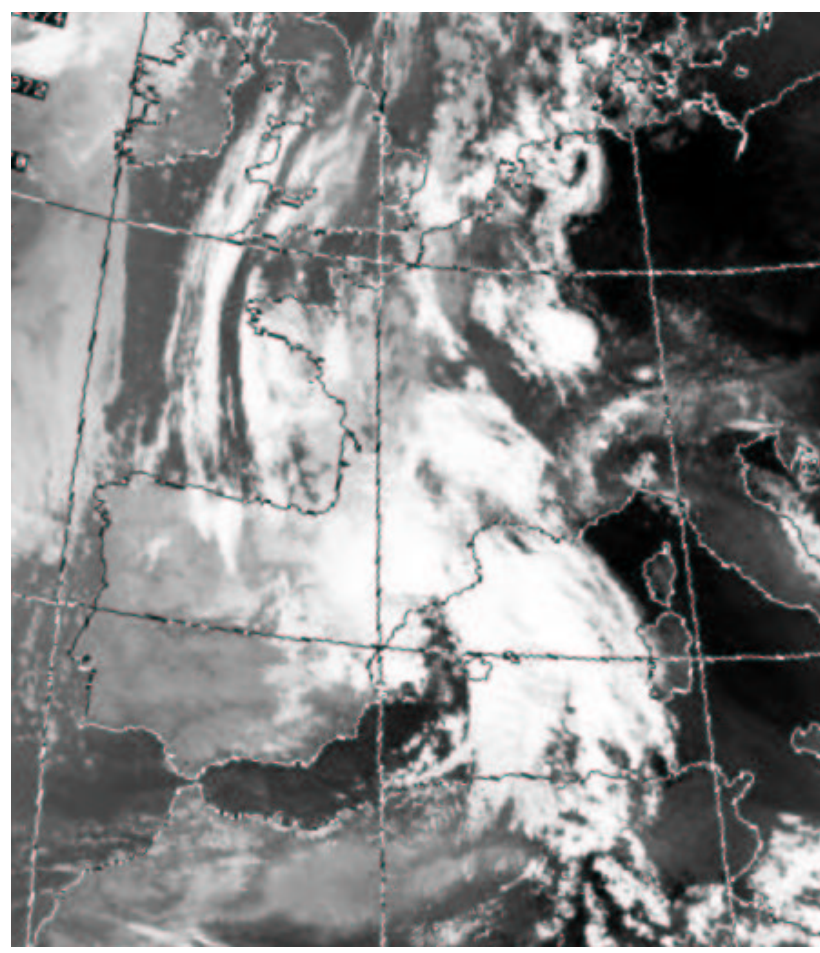

Fig. 4. Infrared NOAA image at 10 June, 04:26 UTC.

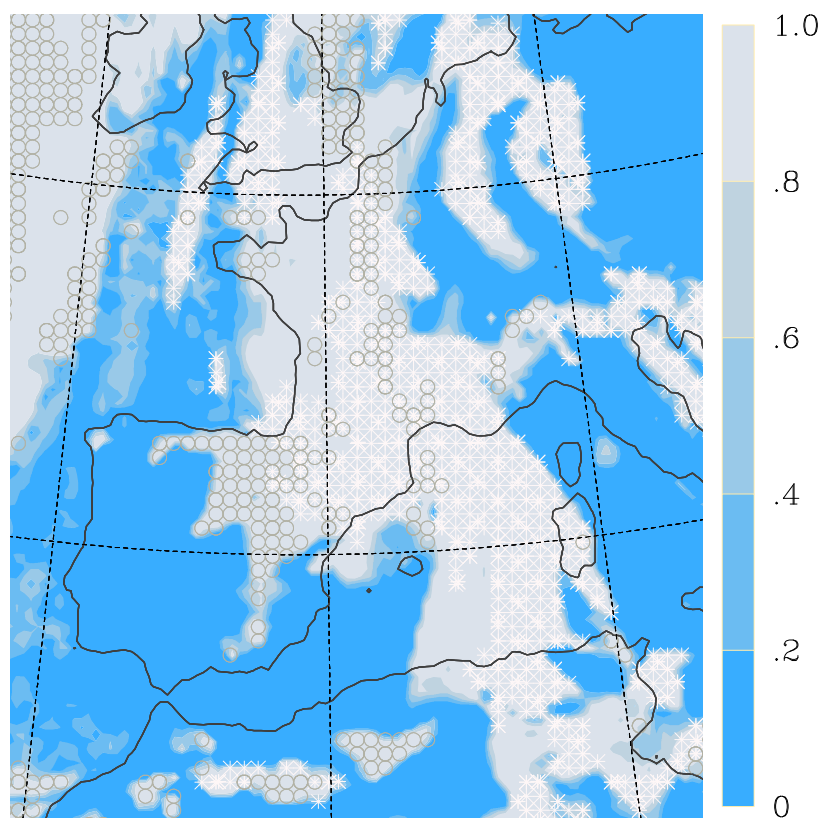

Fig. 5. 28.5 h cloud cover forecast valid at 10 June, 04:30 UTC. BOLAM model with the Louis PBL scheme (B-L experiment). Circles denote low clouds and crosses high clouds.

a larger area in order to show the entire precipitation pattern associated with the cyclonic area. Due to the insufficient resolution and the parameterized convection, the precipitation maxima are severely underestimated by the model. However, the B-L experiment (Fig. 7) gives a secondary maximum of

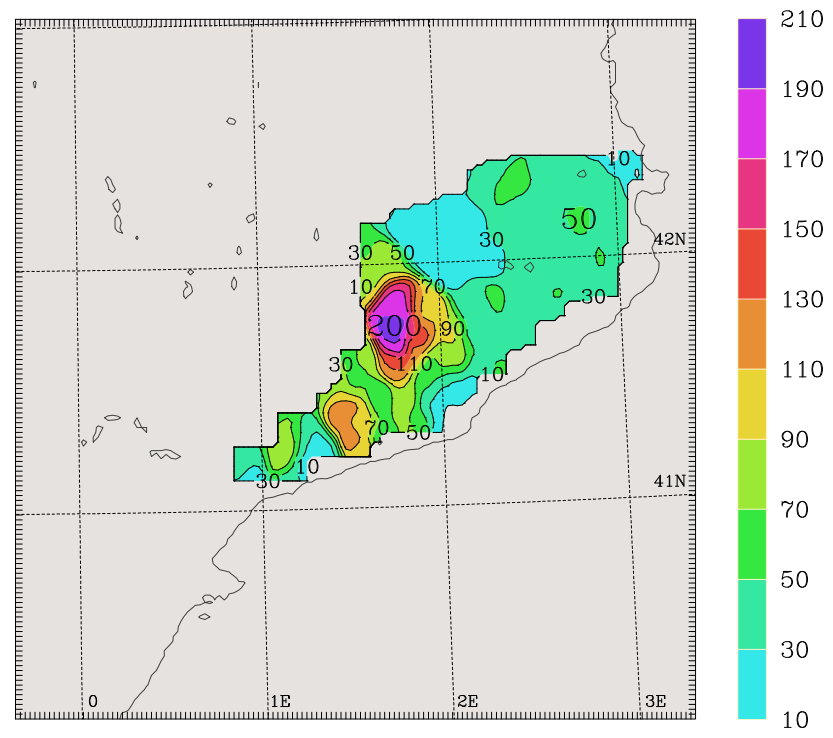

Fig. 6. Observed 24-h accumulated precipitation in the period ending 10 June, 12:00 UTC. Raingauges measurements are reanalyzed over the 1/50 degree grid of the MOLOCH model. Meridians and parallels are drawn every 1 degree.

$92 \mathrm{~mm}$ (half of which produced by the convective scheme) over Catalonia, consistently with the position of the observed maximum. In the B-EL case (Fig. 8), the main precipitation feature is displaced to the south-east but still far from observed. At low resolution, the results of the two turbulence schemes do not appear significantly different, at least for the case under examination. A detailed comparison between observed and simulated precipitation is made below regarding the higher resolution model.

\subsection{MOLOCH simulations}

The MOLOCH model at 1/50 degree resolution is nested directly into the B-L simulation, with boundary conditions updated every $1.5 \mathrm{~h}$. The area of MOLOCH, indicated in Fig. 2, is covered by $200 \times 194$ grid points with 50 vertical levels. The B-L experiment has been chosen here because the cyclone intensity is more similar to the observed one. The high resolution model covers the same time period as BOLAM. As done previously, two MOLOCH simulations are performed, one with the Louis (hereafter referred to as $\mathrm{M}-\mathrm{L}$ ) and the other with the $E-\ell$ (M-EL) turbulence closure schemes, respectively.

Figures 9 and 10 report the 24-h accumulated precipitation for the M-L and M-EL simulations, respectively. As expected, the precipitation pattern shows a much smaller space scale and higher intensity that the corresponding BOLAM fields. Differences between the Louis and the $E-\ell$ schemes are now relevant, not only on precipitation fields but also on other variables such as temperature, humidity and wind. Such differences are not confined to the boundary layer but extend to mid-tropospheric levels, especially where convection is present. The comparison between QPF fields indicates 


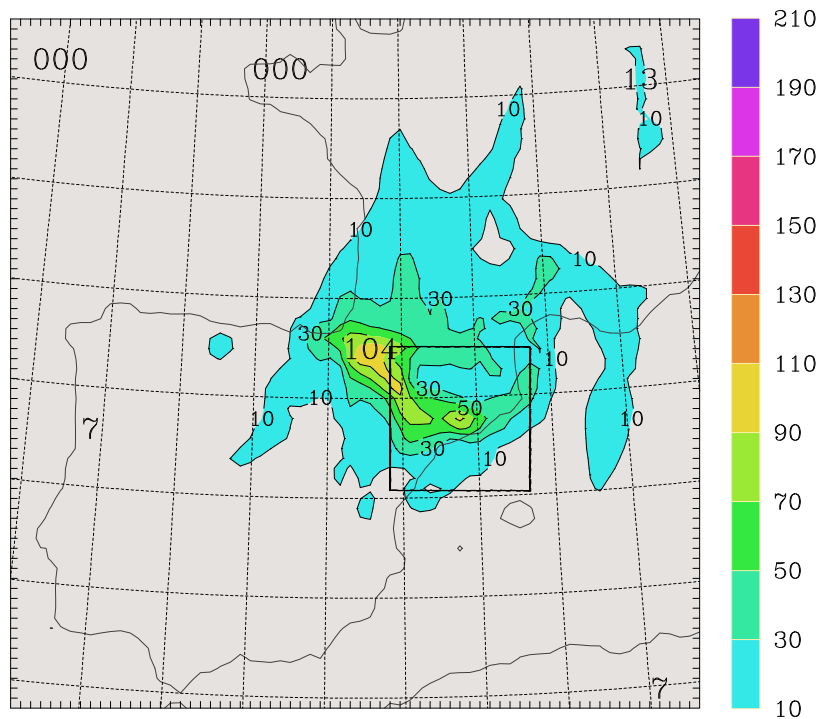

Fig. 7. Simulated 24-h accumulated precipitation in the period ending 10 June, 12:00 UTC. BOLAM model with the Louis PBL scheme (B-L experiment). The area identified by the box corresponds to the area in which MOLOCH precipitation (Figs. 9 and 10) is shown.

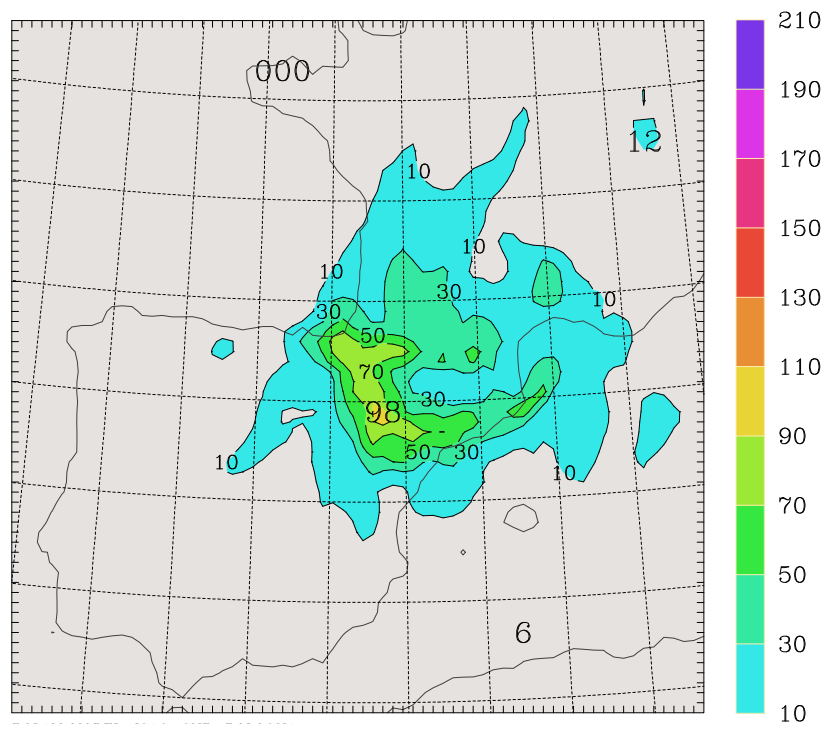

Fig. 8. Simulated 24-h accumulated precipitation in the period ending 10 June, 12:00 UTC. BOLAM model with the $E-\ell$ PBL scheme (B-EL experiment).

that in the M-EL case a realistic convective system develops producing accumulated precipitation very close to the observed one, both in intensity and position (compare Fig. 10 with Fig. 6). Inspection at the hourly precipitation fields reveals a multiple squall line evolution with a prefrontal convective system developing at 00:00 UTC and remaining almost stationary for more than $6 \mathrm{~h}$ in the main precipitation area of Fig. 10.

Figure 11 shows the sequence of 3-hourly accumulated precipitation maxima computed over the area where rain-

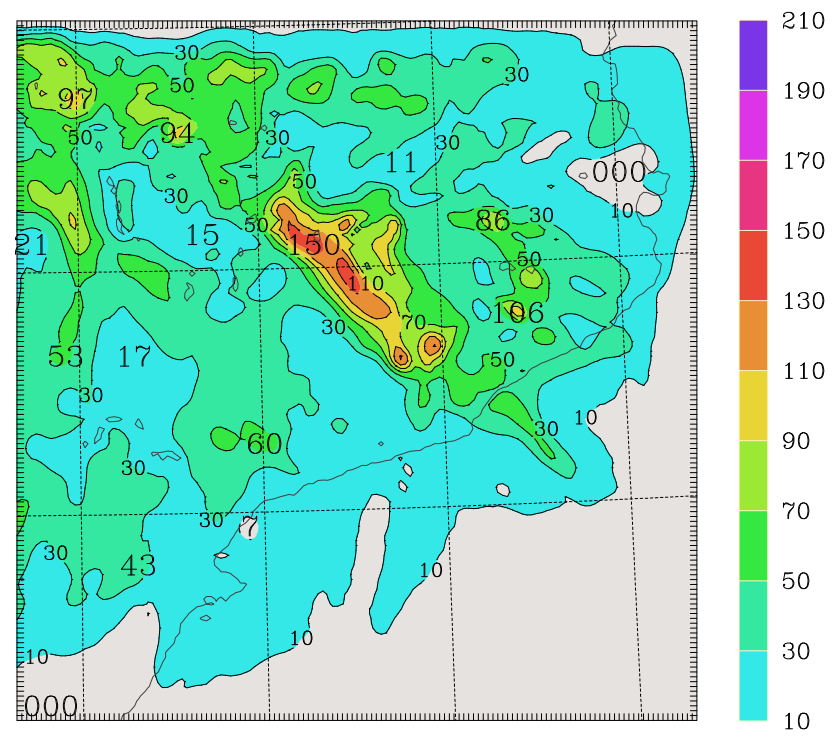

Fig. 9. Simulated 24-h accumulated precipitation in the period ending 10 June, 12:00 UTC. MOLOCH model with the Louis PBL scheme (M-L experiment).

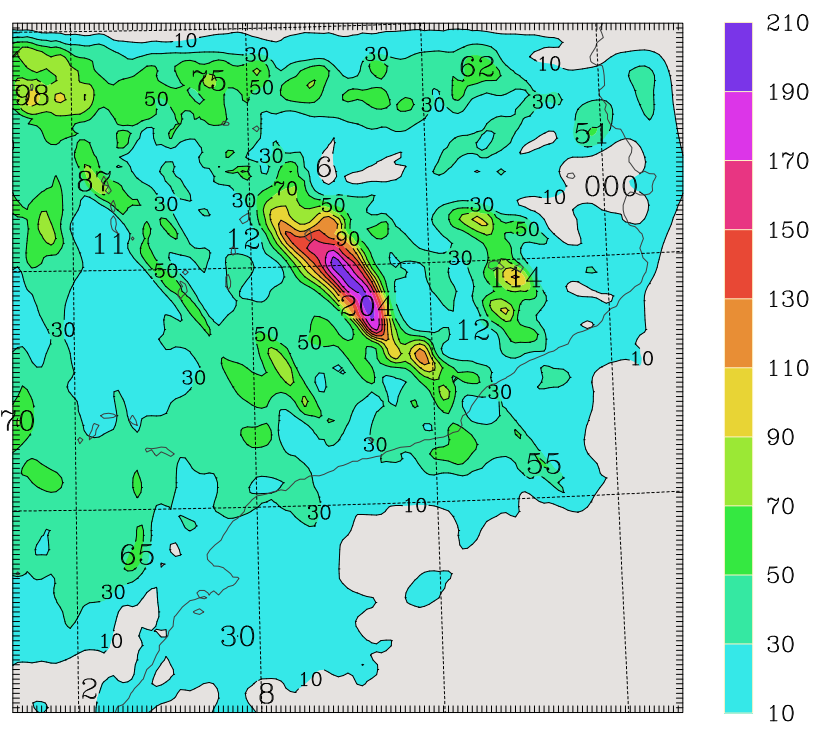

Fig. 10. Simulated 24-h accumulated precipitation in the period ending 10 June, 12:00 UTC. MOLOCH model with the $E-\ell$ PBL scheme (M-EL experiment).

gauges data are avalaible (see Fig. 6). The simulated precipitation peaks are delayled of about $3 \mathrm{~h}$ compared with the observations. It can be noted, however, that the model precipitation maxima are located sligthly north-westward of the monitored area. Again the M-EL simulation performs significantly better than the M-L one.

Figure 12 shows the $10 \mathrm{~m}$ wind field of the M-EL experiment at the time of the highest rainfall rate. An area of pronounced convergence of different air streams into the region of convection can be noticed. The transport of warm air is associated with the south-easterly flow ahead of the cold front. 


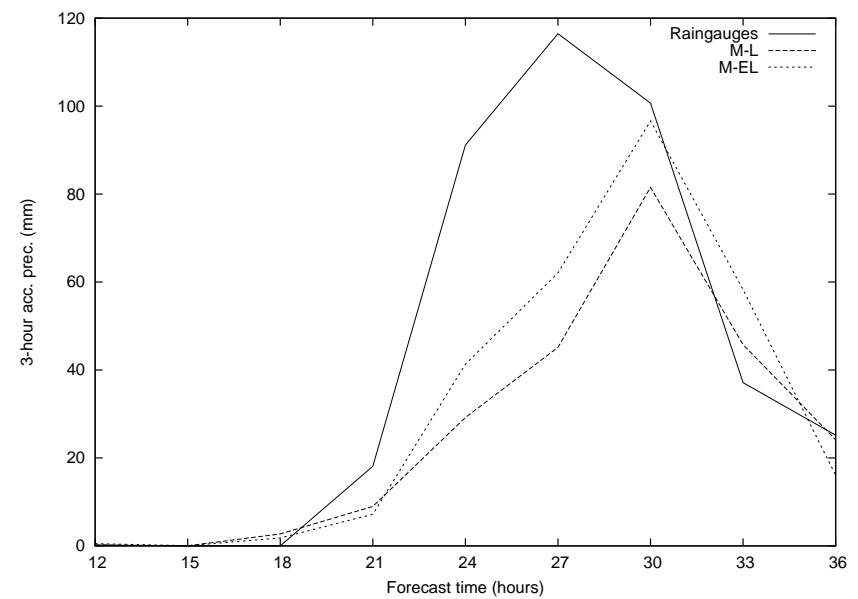

Fig. 11. 3-hourly accumulated precipitation maxima computed over the area where raingauges data are avalaible (see Fig. 6). Continuous line: observations (raingauges), longer dashed line: MOLOCH model with the Louis PBL scheme (M-L experiment), shorter dashed line: MOLOCH model with the $E-\ell$ PBL scheme (M-EL experiment)

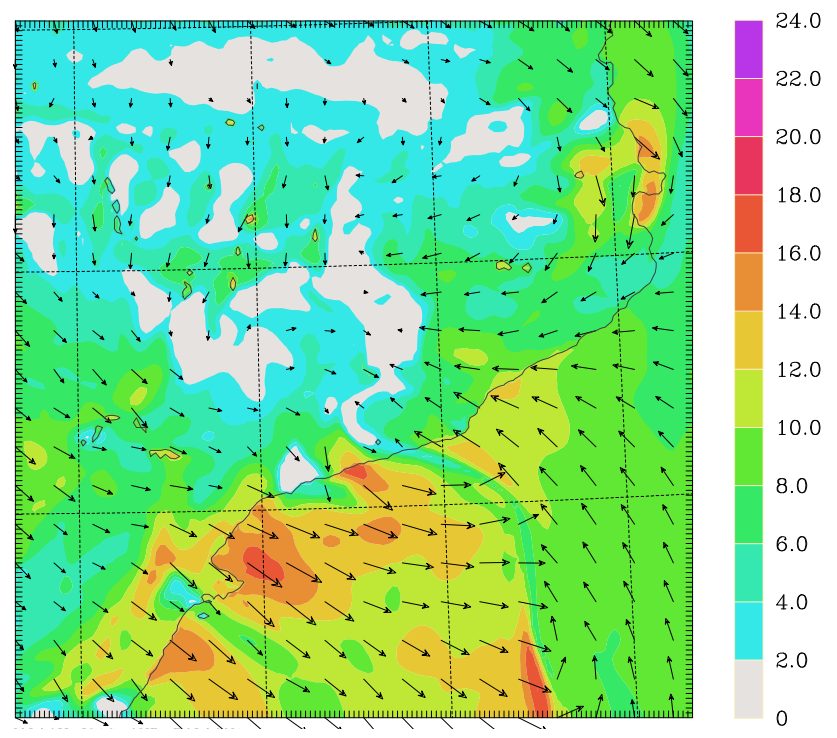

Fig. 12. $27 \mathrm{~h} 10 \mathrm{~m}$ wind forecast valid at 10 June, 03:00 UTC. MOLOCH model with the $E-\ell$ PBL scheme (M-EL experiment).

The post frontal cold flow splits into two main branches: one is the main nort-westerly wind (Cierzo) flowing in the Ebro valley with increasing speed near the coast and over the sea, and the other turns anticyclonically around the eastern flank of the Pyrenees. In addition, a weak northerly flow crosses the Pyrenees along the main valleys.

In general, the high resolution M-EL experiment shows more intense and coherent updrafts in the unstable convective areas. This indicates that, at least for the case under examination, the higher order turbulence closure scheme is more suitable for explicit simulation of convection. Additional testing, however, is required to draw more general conclusions.

\section{Conclusions}

In this work, two different PBL parameterizations have been tested with the goal of assessing the impact of turbulence closures on quantitative precipitation at different resolutions. One formulation consists of a modification of the Louis (1979) scheme which is based on local stability functions. The other is based on the $E-\ell$ turbulence closure with mixing length specified as a non local function of stability and TKE.

The two formulations have been tested at $1 / 5$ and $1 / 50$ degree resolution using the BOLAM and MOLOCH model, respectively. At low resolution, differences are small and cannot be easily interpreted. At high resolution, the $E-\ell$ scheme gives more accurate results in terms of location, timing and total amount of precipitation. In order to roughly determine whether the differences in precipitation amounts are due to the different vertical diffusion schemes or to the chaotic nature of small scale convection, the M-L and M-EL experiments (conducted with the non-hydrostatic model) have been repeated by changing some model parameters like soil and vegetation types. In all the experiment performed, the difference between M-L and M-EL was found to be stable.

A good agreement between observed and modeled precipitation cannot be expected in general in forecasting convective precipitating systems. One advantage here, with respect to real time forecasting or to the other simulations of the same case presented in Mariani et al. (2005), is in the use of gridded analysis (in place of forecast) fields as boundary conditions. One other reason is that here convection is embedded in a coherent larger scale system and is triggered by the strong dynamical processes that are associated with the cyclone, its frontal structure and other sub-synoptic mesoscale flow features.

An exhaustive comparison between the Louis and $E-\ell$ schemes is beyond the scope of this study. On one hand, this case study is too complex to be suitable for a more elementary interpretation of the physical differences between the two parameterizations and, on the other hand, it is impossible to draw definite conclusions from the inspection of a single case study. However, the results of this work are in agreement with those of other studies (Xu and Zhao, 2000; Lynn et al., 2001; Wisse and de Arellano, 2004), that show the benefits of the use of TKE based PBL parameterization on QPF. Especially in the case of convective resolving models, TKE based schemes can provide better transport of moisture, heat and momentum through the PBL and within clouds than first order closure schemes (Lynn et al., 2001). Indeed, the $E-\ell$ scheme produces a deeper moist boundary layer and a stronger inversion a the top of it that result in a stronger low level convergence of moisture and favours the reproduction of more extreme and localized precipitation rates.

Acknowledgements. This work was supported by the HYDROPTIMET Interreg IIIB MEDOCC EU Program. All the data (the ECMWF analysis and raingauge data of the Agencia Catalana de l'Aigua) were obtained in the context of the same project. The authors would like to thank the GAMA team of the University 
of Barcelona (Spain) and S. Mariani of APAT (Italy) for their provision and assistance with the rainfall data.

Edited by: M.-C. Llasat

Reviewed by: L. Ramis and three other referees

\section{References}

Beljaars, A. C. M.: The impact of some aspects of the boundary layer scheme in the ECMWF model, ECMWF seminar proceedings on Parameterization of subgrid scale physical processes, Reading, UK, 1995.

Beljaars, A. C. M. and Holtslag, A. S. M.: On flux parameterization over land surface for atmospheric models, J. Atmos. Sci., 30, 327-341, 1991.

Beljaars, A. C. M. and Viterbo, P.: The role of the boundary layer in a numerical weather prediction model, in: Clear and cloudy boundary layers Mechanics, edited by: Holtslag, A. A. M. and Duynkerke, P. G., North Holland Publishers, 1999.

Billet, S. and Toro, E. F.: On WAF-type schemes for multidimensional hyperbolic conservation laws, J. Comput. Phys., 130, 124, 1997.

Blackadar, A. K.: The Vertical Distribution of Wind and Turbulent Exchange in a Neutral Atmosphere, J. Geophys. Res., 67, 30953102, 1962.

Bougeault, P. and Lacarrere, P.: Parameterization of orographyinduced turbulence in a mesobetascale model, Mon. Wea. Rev., 117, 1872-1890, 1989.

Browning, K. A.: Organization and internal structure of synoptic and mesoscale precipitation systems in mid-latitudes, Radar in Meteorology, edited by: Atlas, D., AMS, Boston, Mass., 1990.

Buzzi, A., Fantini, M., Malguzzi, P., and Nerozzi, F.: Validation of a limited area model in cases of Mediterranean cyclogenesis: surface fields and precipitation scores, Meteorol. Atmos. Phys., 53, 137-153, 1994.

Canuto, V. M., Minotti, F., Ronchi, C., Ypma, R. M., and Zeman, O.: Second Order Closure PBL Model with New ThirdOrder Moments: Comparison with LES Data., J. Atmos. Sci., 51, 1605-1618, 1994.

Deardorff, J. W.: Convective velocity and temperature scales for the unstable planetary boundary layer and for Rayleigh convection, J. Atmos. Sci., 7, 1211-1213, 1970.

Deardorff, J. W.: Stratocumulus-capped mixed layers derived from a three dimensional model, Boundary-Layer Meteorol., 7, 199226, 1980 .

Drofa, O. and Malguzzi, P.: Parameterization of microphysical processes in a non hydrostatic prediction model, Proc. 14th Intern. Conf. on Clouds and Precipitation (ICCP), Bologna, IT, 2004.

Dyer, A. J.: A review of flux-profile relationships, Boundary-Layer Meteorol., 7, 363-372, 1974.

Hinze, J. O.: Turbulence, McGraw-Hill Publishing Co., New York, 1975.

Hogstrom, U.: Non-dimensional wind and temperature profiles in the atmospheric surface layer: A re-evaluation, Boundary-Layer Meteorol., 42, 55-78, 1988.

Hogstrom, U.: Review of some basic characteristics of the Atmospheric Surface Layer, Boundary-Layer Meteorol., 78, 215-246, 1996.

Kain, J. S.: The Kain-Fritsch convective parametrization: an update, J. App. Meteorol., 43, 170-181, 2004.
Kain, J. S. and Fritsch, J. M.: A one-dimensional entraining/detraining plume model and its application in convective parameterization, J. Atmos. Sci., 47, 2784-2802, 1990.

Kolmogorov, A. N.: The Local structure of turbulence in incompressible viscous fluid for very large Reynolds numbers, Dokl. Akad. Nauk SSSR, 30, 1941.

Kolmogorov, A. N.: The equations of turbulent motion in an incompressible fluid, Izv. Acad. Sci. USSR, Phys., 6, 56-58, 1942.

Llasat, M., Rigo, T., and Barriendos, M.: The "Montserrat-2000" flash-flood event: A comparison with the floods that have occurred in the northeastern Iberian Peninsula since the 14th century, Int. J. Climatol., 23, 453-469, 2003.

Louis, J. F.: A Parametric Model of the Vertical Eddy Fluxes in the Atmosphere, Boundary-Layer Meteorol., 17, 18-202, 1979.

Lynn, B. H., Stauffer, D. R., Wetzel, P. J., Tao, W. K., Alpert, P., Perlin, N., Baker, R. D., Munoz, R., Boone, A., and Jia, Y. Q.: Improved simulation of Florida summer convection using the PLACE land model and a 1.5-order turbulence parameterization coupled to the Penn State-NCAR mesoscale model, Mon. Wea. Rev., 129, 1441-1461, 2001.

Mariani, S., Casaioli, M., Accadia, C., Llasat, C., Pasi, F., Davolio, S., Elementi, M., Ficca, G., and Romero, R.: A limited area model intercomparison on the "Montserrat-2000" flashflood event using statistical and deterministic methods, Nat. Hazards Earth Syst. Sci., in press, 2005.

Mlawer, E. J., Taubman, S. J., Brown, P. D., Iacono, M. J., and Clough, S. A.: Radiative transfer for inhomogeneous atmospheres: RRTM, a validated correlated-k model for the longwave, J. Geophys. Res., 102D, 16663-16 682, 1997.

Monin, A. S. and Obukhov, A.: Basic laws of turbulence mixing in the surface layer of the Atmosphere., Trudy Geophys. Inst. AN SSSR, 24, 163-187, 1955.

Morcrette, J. J.: Radiation and cloud radiative properties in the ECMWF operational weather forecast model, J. Geophys. Res., 96D, 9121-9132, 1991.

Nieuwstadt, F. T. M.: The turbulent structure of the stable, nocturnal boundary layer, J. Atmos. Sci., 41, 2202-2216, 1984.

Panofsky, H. A., Tennekes, H., Lenschow, D. H., and Wyngaard, J. C.: The Characteristics of Turbulent Velocity Components in the Surface Layer Under Convective Conditions, BoundaryLayer Meteorol., 11, 355-361, 1977.

Prandtl, L.: Zur turbulent Stromung in Rohren und langs Platten, Ergebn. Aerodyn. Versuchsanst, 4, 18-29, 1932.

Prandtl, L.: Über die ausgebildete Turbulenz, Z. Angew. Math. Mech., 5, 136-139, 1945.

Pressman, D. J.: Chislennaja model' gidrotermicheskikh processov v pochve kak chast' skhemy mezomasshtabnogo prognoza (A numerical model of hydrothermical processes in soil as a part of a mesoscale weather forecast scheme), Meteorologiya i gidrologiya (Meteorology and Hydrology), 11, 62-75, in Russian, 1994.

Ritter, B. and Geleyn, J.: A comprehensive radiation scheme for numerical weather prediction models with potential applications in climate simulations, Mon. Wea. Rev., 120, 303-325, 1992.

Rodi, W.: Turbulence Models and their Applications in Hydraulics - A State of Art Review (Report), Institut fur Hydromechanik and University of Karlsruhe, 1980.

Romero, R., Martin, A., Homar, V., Alonso, S., and Ramis, C.: Predictability of prototype flash flood events in the Western Mediterranean under uncertainties of the precursor upper-level disturbance: The Hydroptimet case studies, Nat. Hazards Earth Syst. Sci., accepted, 2005. 
Schultz, P.: An explicit cloud physics parameterization for operational numerical weather prediction, Mon. Wea. Rev., 123, 33313343, 1995.

Speziale, C. G.: Analytical methods for the development of Reynolds-stress closures in turbulence, Ann. Rev. Fluid Mech., 23, 107-157, 1991.

Stull, R. B.: An Introduction to Boundary Layer Meteorology, Kluwer Academic Publishers, Dordrecht, The Netherlands, 666 pp., 1988.

Viterbo, P., Beljaars, A. C. M., Mahfouf, J.-F., and Teixeira, J.: The representation of soil moisture freezing and its impact on the stable boundary layer, Quart. J. Roy. Meteor. Soc., 125, 2401-2426, 1999.

Wang, D., Large, W. G., and McWilliams, J. C.: Large-eddy simulation of the equatorial ocean boundary layer: Diurnal cycling, eddy viscosity, and horizontal rotation, J. Geophys. Res., 101, 3649-3662, 1996.
Webster, C. A. G.: An experimental study of turbulence in a density stratified shear flow, J. Fluid Mech., 19, 221-245, 1964.

Wisse, J. S. P. and de Arellano, J. V. G.: Analysis of the role of the planetary boundary layer schemes during a severe convective storm, Ann. Geophys., 22, 1861-1874, 2004,

SRef-ID: 1432-0576/ag/2004-22-1861.

$\mathrm{Xu}, \mathrm{L}$. R. and Zhao, M.: The influences of boundary layer parameterization schemes on mesoscale heavy rain system, Adv. Atmos. Sci., 17, 458-472, 2000.

Young, S. T. B.: Turbulence measurements in a stably-stratified turbulent shear flow, Rep. QMC-EP 6018, Queen Mary College of London, 1975.

Zampieri, M.: Comparison among First, Second and Third Order CBL Models, Proc. of the 16th Symposium on Boundary Layers and Turbulence, Portland, ME, 2004. 